\title{
Useful Teaching Strategies in STEMM (Science, Technology, Engineering, Mathematics, and Medicine) Education during the COVID-19 Pandemic
}

\author{
Frank C. Church ${ }^{1, *}$, Scott T. Cooper ${ }^{2}$, Yolanda M. Fortenberry ${ }^{3}$, Laura N. Glasscock ${ }^{4}$ and Rebecca Hite $^{5}$ (D) \\ 1 Department of Pathology and Laboratory Medicine, The University of North Carolina School of Medicine, \\ Chapel Hill, NC 27599, USA \\ 2 Department of Biology, University of Wisconsin-La Crosse, La Crosse, WI 54601, USA; scooper@uwlax.edu \\ 3 Biology Department, Case Western Reserve University, Cleveland, OH 44106, USA; ymf4@case.edu \\ 4 Department of Biology, Winthrop University, Rock Hill, SC 29733, USA; glasscockl@winthrop.edu \\ 5 Department of Curriculum \& Instruction, Texas Tech University, Lubbock, TX 79409, USA; \\ Rebecca.hite@ttu.edu \\ * Correspondence: fchurch@med.unc.edu
}

\section{check for} updates

Citation: Church, F.C.; Cooper, S.T.; Fortenberry, Y.M.; Glasscock, L.N.; Hite, R. Useful Teaching Strategies in STEMM (Science, Technology, Engineering, Mathematics, and Medicine) Education during the COVID-19 Pandemic. Educ. Sci. 2021, 11,752. https://doi.org/10.3390/ educsci11110752

Academic Editors: James Albright and Han Reichgelt

Received: 27 October 2021

Accepted: 17 November 2021

Published: 19 November 2021

Publisher's Note: MDPI stays neutral with regard to jurisdictional claims in published maps and institutional affiliations.

Copyright: (c) 2021 by the authors. Licensee MDPI, Basel, Switzerland. This article is an open access article distributed under the terms and conditions of the Creative Commons Attribution (CC BY) license (https:// creativecommons.org/licenses/by/ $4.0 /)$.

\begin{abstract}
The impacts of the COVID-19 pandemic throughout the world continue. These impacts influence many aspects of life, work, healthcare, and education in the U.S., which are drastically affected by the COVID-19 pandemic. Thus, a considerable challenge to tertiary-level education has been how to adapt our teaching styles and modalities to keep all stakeholders (students, faculty, teaching assistants, and staff) safe in lectures and labs. This viewpoint presents 15 teaching lessons and tips for undergraduate and graduate STEMM (Science, Technology, Engineering, Mathematics, and Medicine) education for face-to-face, hybrid, and distance learning. The goal was to describe teaching strategies that could be adaptable to most STEMM courses, independent of the classroom size, which is valuable for those educational settings capable of migrating from a classroom to either a hybrid or strictly online teaching environment. Although some of these teaching tips were straightforward, we believe collectively that they (1) provide safety and stability to the students and the instructors; (2) help to improve communications between faculty and students that the pandemic had strained; (3) strengthen student attention; (4) facilitate the transition from the classroom to online teaching; (5) enable the use of new technologies; and (6) offer teaching practices we imagined for educational scenarios post-SARS-CoV-2. Finally, we hope these teaching strategies offer valuable insight as we continue to navigate STEMM education during the ongoing COVID-19 pandemic.
\end{abstract}

Keywords: SARS-CoV-2; COVID-19; pandemic; STEMM; teaching practices

\section{Introduction}

\subsection{COVID-19}

Before developing effective vaccines to the coronavirus named severe acute respiratory syndrome coronavirus 2 (SARS-CoV-2), much of the world's societies lived in containment modes in an attempt to reduce the threat of infection and the spread of SARS-CoV-2 from person to person [1-4]. These containment strategies included closing common borders between countries, stay-at-home or 'lockdown' orders, limiting traveling within a given country, washing one's hands frequently with anti-microbial reagents, social distancing (in staying 6 feet apart), and wearing protective masks [1-4]. A study of educational settings in California recommended these mitigation policies for face-to-face instruction, such as masking with adequate supplies and designated 'unmasking zones' with distanced seating [5]. Depending on the amount of adherence to policy, scientists found minimal SARS-CoV-2 transmission [5]. A meta-analysis of viral transmission studies concluded that individuals seated one meter apart greatly diminished the transmission of SARS-CoV-2 [6]. These studies demonstrate that mitigation strategies reduce COVID-19 
(the disease caused by SARS-CoV-2 was termed coronavirus disease 2019) transmission in an education environment, but do not eliminate transmission of virus entirely.

As of 26 October 2021, worldwide, there have been 243,857,028 confirmed cases of COVID-19, including 4,953,246 deaths, reported to WHO [7]. In the USA, as of 26 October 2021, there have been 45,107,253 confirmed cases of COVID-19 with 730,306 deaths, reported to WHO [7]. As of 22 October 2021, a total of 422,902,300 vaccine doses have been administered in the USA [7]. Given the virulence of SARS-CoV-2, coupled with the morbidity and mortality of COVID-19, tertiary level educators have engaged in strategies to continue STEMM (Science, Technology, Engineering, Mathematics, and Medicine) education safely in varying modalities of socially distanced hybrid and remotely online.

\subsection{STEMM Education in the Time of COVID-19}

The COVID-19 pandemic began in earnest in the USA in March of 2020 [8,9], about mid-semester of the spring term. At that time, universities/colleges were developing and implementing mitigation strategies $[10,11]$. Direct student-to-student and student-tofaculty contact, typically found in a classroom setting, seemed unlikely for the rest of 2020 and into 2021. Thus, the COVID-19 pandemic challenged educators worldwide to either create or adopt new and innovative tools, techniques, and strategies to teach successfully and, at the same time, reduce SARS-CoV-2 infection from person to person [12-18].

Moreover, undergraduate and graduate STEMM education typically stress the importance of STEMM faculty engagement with students [19-23]. This reduction in student and faculty interactions does not imply that STEMM classes have been grievously affected by the COVID-19 pandemic. Instead, the co-authors of this viewpoint are all involved in teaching students or researching aspects at various levels of STEMM education and found methods and strategies successful in educating STEMM under/graduate students. Our overall goal was to provide teaching strategies that would be adaptable across a broad set of STEMM courses, useful in a wide range of class sizes, and (hopefully) feasible for those with capabilities to go from a classroom to either a hybrid or strictly online teaching environment. Thus, this viewpoint highlights 15 teaching strategies used by the co-authors during the past 18 months of the COVID-19 pandemic. The SARS-CoV-2 virus has changed the world in many respects, and it has likely changed the way we approach STEMM education in the present and future.

\section{Compilation of Teaching Lessons and University Profiles}

The co-authors of this viewpoint compiled a list of each contributing teaching practice they have used throughout the COVID-19 pandemic in STEMM classrooms they teach or research. It is important to note that while we were not testing a hypothesis about STEMM education, we provide educational strategies that have proven useful in our teaching environments during the COVID-19 pandemic. Furthermore, although not derived from a poll of our university's faculty, we each represent STEMM educators at five different institutions of higher education in the USA. A summary describing our universities (listed alphabetically) is given below. All teaching practices involved transitioning from teaching face-to-face to an online learning format.

(1) Case Western Reserve University, Cleveland, $\mathrm{OH}$ (School and Location), Private (Type of Institution), Semester (Academic Calendar), 5433 (Total Undergraduate Enrollment, Fall, 2020), and with a population of 385,382 (2019);

(2) Texas Tech University, Lubbock, TX (School and Location), Public (Type of Institution), Semester (Academic Calendar), 33,269 (Total Undergraduate Enrollment, Fall, 2020), and with a population of 253,851 (2019);

(3) University of North Carolina at Chapel Hill, Chapel Hill, NC (School and Location), Public (Type of Institution), Semester (Academic Calendar), 19,399 (Total Undergraduate Enrollment, Fall, 2020), and with a population of 60,998 (2019); 
(4) University of Wisconsin-La Crosse, La Crosse, WI (School and Location), Public (Type of Institution), Public (Type of Institution), Semester (Academic Calendar), 9479 (Total Undergraduate Enrollment, Fall, 2020), and with a population of 51,666 (2019);

(5) Winthrop University, Rock Hill, SC (School and Location), Public (Type of Institution), Semester (Academic Calendar), 4406 (Total Undergraduate Enrollment, Fall, 2020), and with a population of 73,334 (2019).

Our teaching experiences in STEMM education range from:

(a) introduction to biology, genetics, and molecular biology to undergraduates (Cooper and Glasscock),

(b) biomedical sciences (disease biology, immunology, and hematology) to undergraduates and graduate students (Cooper, Fortenberry, Glasscock, and Church),

(c) immunology and hematology to medical students (Church), and finally,

(d) exploring the experiences of STEMM faculty and their learning assistants (LAs) in undergraduate STEMM courses, such as Calculus II (Hite).

Class sizes for the co-authors range from a small classroom ( $<25$ students), mid-size classroom ( 25-60 students), medium classroom (61-100 students), to a large classroom (>100 students).

\section{Results}

\subsection{Useful Teaching Strategies for STEMM Teaching during the COVID-19 Pandemic}

Adapting to the COVID-19 pandemic provided some critical challenges faced in STEMM education. In composing our STEMM teaching lessons and tips list for this viewpoint, we considered their importance contained within these five key issues:

(1) safety of students and teaching faculty/teaching assistants/staff;

(2) transferring content from an in-classroom setting to an online setting;

(3) keeping students engaged;

(4) mitigating technology-related issues;

(5) ensuring fair grading/assessment.

\subsection{Safety of Students and Teaching Faculty/Teaching Assistants/Staff}

Stay Informed of Changing University Policies When Teaching from a Distant Site

This may seem obvious, but it is crucial for teaching faculty to understand the most up-to-date policies associated with teaching, instruction, SARS-CoV-2 testing, meeting, and any other "rule" or "guideline" introduced by your school leaders. It is very easy to miss some memo detailing minor or substantial policy changes; thus, stay informed. Even if one disagrees with a campus policy, it is vital to provide students with consistent messaging and lead by example.

\subsection{Transferring Knowledge from an In-Classroom Setting to an Online Setting \\ 3.3.1. Use a Variety of Technology and Teaching Methods}

Online teaching provides an opportunity to use various technology and teaching techniques to cover topics and reach students in different ways. Professors and instructors should use combinations of narrated closed-captioning to make lectures more accessible, provide copies of the non-narrated lectures for notetaking, and employ whiteboard recordings of mechanism/pathway demonstrations. Furthermore, one can utilize interactive videos such as Howard Hughes Medical Institute (HHMI) Biointeractive activities, leverage simulated versions of lab exercises, and pre-record lab exercises. While pre-recording content, one may wish to break long lectures into shorter sections. This allows students to re/locate the content they may wish to view again and allows easier editing in the future. Giving students access to these resources before a synchronous class meeting frees up a substantial amount of synchronous or in-class time for group and small group discussions and activities, essentially flipping the class. Further, students can use recorded resources to review and study at their leisure. 


\subsubsection{Creating Active Learning Online Material with Zoom}

An essential aspect of many courses is active learning, which uses small group-derived interactions (4-6 students/group) to promote student engagement. Adapting Zoom for active learning and STEMM [24,25], we suggest the following seven points:

- When using Zoom breakout rooms, keep the same students in the same group throughout the class term. This consistency helps to facilitate camaraderie among students and fosters a peer support system. There is a new feature in Zoom that facilitates group assignments in breakout rooms.

- Task students with meeting their groups outside of class to complete their group assignments via Zoom. This group accountability creates a structure to prioritize their class assignments and further supports the concept of the group as team.

- Post recorded lectures and labs the same day they are given (if possible).

- Record and post exam review sessions for review and if students miss them.

- If a teaching assistant (TA) is available, ask them to compile the most relevant messages/questions posted to your institution's Learning Management System (LMS). By having your TA curate questions from the LMS, you will have more information to prepare for the lecture. Furthermore, this gives the professor a good check on level of comprehension/confusion from the previous lecture that can be used to inform the next lecture.

- Some faculty disable the messaging feature in Zoom because it can be a distraction during the lecture; however, enabling the messaging feature encourages the participation of the quiet/reserved students. Thus, we recommend keeping the message function on during all lectures after class norms are discussed in regard to proper chat etiquette (e.g., no use of profanity, no cyberbullying classmates, report any disruptive actions to the instructor or professor). In addition, the pop-up feature for messaging can be disabled so the instructor can check messages when they choose during a lecture.

- If one utilizes games in one's teaching, search for online updates as many companies have adapted quickly to the altered teaching landscape created by the COVID-19 pandemic. Do note that some interactive programs/games/tools are not adaptable for a Zoom platform.

\subsubsection{Laboratory-Based Sections/Courses}

- Professors may use a combination of simulated lab exercises widely available online, and lab exercises recorded in-house, using a GoPro camera. Video recorded from a GoPro is from a first-person view so that students can watch as the professor performs the lab exercise from the professor's point of view. The recorded labs are ideal for small groups to pause and rewind periodically to discuss, analyze the data, and form conclusions.

- An online synchronous lab experience allows the professor to work with students in small groups to discuss various laboratory techniques and review multiple primary research articles that utilize these techniques. The professor introduces the technique, and students review multiple primary research articles utilizing the techniques, analyze data generated by the techniques, and critique statistical analyses and conclusions. Although this does not replace the bench-top lab experience, students gain experience analyzing and critiquing multiple data sets using different data sources. Students can also be given results from previous semesters or existing data sets to analyze. Bioinformatics and statistical analysis are also good online synchronous options for labs.

\subsection{Keeping Students Engaged}

\subsubsection{Organizing Student Meetings Using Zoom}

Professors are encouraged to use a variety of activities and discussions during synchronous class meetings. Small groups in breakout rooms are beneficial in engaging the students during class time. The professor should frequently visit each breakout group 
during small group discussions to ensure each student is participating. Students who are usually silent in the large group sessions may open up and talk to each other and to the professor during the small group time. This is a critical time for the professor to get to know each student individually as they would in the face-to-face classroom setting.

\subsubsection{Creating Ways for Students to Remain Engaged in an Online Class}

An essential aspect of STEMM education is keeping students engaged during class, especially when lecturing online with Zoom. We suggest the following four points:

- Recruit a graduate teaching assistant (GTA) who can assist the professor with scoring class assignments, and act as a liaison between the professor and students. During a Zoom lecture, the professor cannot see all of the students or be able to respond to their questions in real-time; the GTA can be tasked with interacting with students via the chat function. Students may pose their questions to the GTA. The GTA can try to answer the question and if they cannot, they should summarize major questions for the professor. Plan to have time following the end of the lecture to answer these questions aggregated by the GTA. By employing your GTA in this fashion, the student can remain anonymous. This practice is critical because some students hesitate to ask questions in a large group, especially in the whole class Zoom format.

- Randomly call on students to engage in the discussion to help them articulate their ideas aloud as an effective way to think about an idea or concept. Thus, calling on individual students to answer a question or expand on the topic is critical to the student's ability to grasp the concept. Using this practice is particularly important in STEMM because some of the topics are complex. Having students think through how they understand a concept will aid other students in co-constructing their understandings. Additionally, teaching using Zoom will 'force' the students to remain engaged and not become distracted by their phones or surf the web during class time, especially if they realize they may be the next person called to respond to a question. Alternatively, one could adopt the "Think-Pair-Share" approach where students first formulate their own explanation, then pair with another student or group to discuss. Then the instructor can ask groups to share their answers with the entire class.

- Establishing a classroom culture of keeping cameras on during Zoom presentations prevents students from disengaging from other activities (e.g., email, social activity media). This practice is essential for the professor and GTA to gauge to what extent students are grasping the lecture content/concept and not due to visual and social cues.

- Ask students to submit a one-minute paper before each class as a formative assessment. Teaching via Zoom often necessitates recording lectures or posting lectures for the students before class. To ensure that the students review these lectures beforehand, consider requiring students to submit a 1-min paper consisting of one or two questions about the lecture, particularly the complex topics. The one-minute papers are due before class so that the GTA can synthesize their replies. This practice allows the professor to focus on the topics that the students find especially difficult to understand. In addition, one may wish to ask the students to submit a one-minute paper after class to determine how well concepts were understood and the direction of future lectures within the topic.

\subsubsection{Organization of Daily Schedule}

Prepare an organized and concise LMS for each class. For instance, have an individual page for each day with the readings, slides, recorded lectures, and assignments in the exact location. This makes it much easier for students to track what is due each day and where to locate assignment submissions and other course functionalities readily. In addition, consider sending out a regular (i.e., daily, weekly) course message to remind students of upcoming assignments and expectations of the course. This takes the place of the daily announcements one would have made before or after in-person lectures or labs. 


\subsubsection{Increase the Number of Office Hours}

Staying in contact by offering more office hours can go a long way to calming students' nerves. The class will notice your sincerity, and it will pay off with a more focused, relaxed, and ready to learn student (unusual life circumstances notwithstanding). In addition, online office hours are often better attended than in-person office hours.

\subsubsection{Universal Design for Learning Improves Accessibility}

Utilize universal design for learning (UDL) principles to ensure that your material is accessible to all students. UDL all material, including syllabi, assignments, lectures, link, etc. needs to be accessible to all users. Some UDL principles include but are not limited to texts without serifs for ease of reading, images and figures with captioning, and videos with closed captions. Some LMS, such as Blackboard, have tools to scan all documents and give feedback on the accessibility.

\subsubsection{Remain Positive}

The professor's attitude in an online course, especially during a stressful time such as a pandemic, is quickly reflected in the students' attitudes. Therefore, remaining upbeat and emphasizing the positive aspects of learning online is essential. Additionally, connecting with each student, usually in small group sessions, is vital to help make the student more engaged and feel part of the learning community. Call on students by name and make sure all students are addressed on a regular basis. It is easy for students to become lost or "unseen" in an online environment. Actively engaging each student often helps ensure they remain connected. Remind your students that this is not your preferred way to teach either, and you are doing the best you can to help them learn the material.

\subsection{Mitigating Technology-Related Issues}

\subsubsection{Maintain all Online Material for Future Use}

Keep all the online materials one developed. Recorded lectures can be used for students who must miss class or for review. Online quizzes and exams can be used for practice or review. Clearly label that these online materials were recorded during a different semester to avoid confusion if one mentions any assignments or dates in one's recording.

\subsubsection{Flipping a Class from Recorded Lecture Files}

Use online materials to flip a class. Flipping the class means students watch lectures outside of class and participate in learning activities in class. To do this, have students watch recorded lectures or read about topics before class, then use the class time to work on problems, talk about case studies, and task students with making presentations. It is beyond the scope of this viewpoint to describe the logic or utility behind flipping a class lecture; however, see [24-28] for further background.

\subsubsection{Make Sure to Have Adequate Tools to Lecture Online}

Having one's computer laptop with the camera elevated at the appropriate height and distance will matter. Furthermore, a stable internet router system to ensure steady online connections is also very important. Finally, peripherals like good lighting, an external microphone, and speakers for one's computer to enhance communication can improve faculty-student interactions. If one cannot meet in person, optimizing the meeting conditions will help establish the changed routine due to the pandemic.

\subsubsection{Research on Undergraduate STEMM Education}

Research conducted on faculty and their Learning Assistants (LAs) indicated that relationships were fundamental for reestablishing the face-to-face STEMM learning environment online [29]. Fundamental to the success of moving online was in Showing Care and Fostering Relationships between faculty members and LAs followed by Honing Pedagogical Skills and Being Prepared for Class and Students. Developing Content Knowledge in STEMM was 
a lower priority. These findings suggest that LAs wanted specific support in cultivating and maintaining their relationships during the rapid transition from face-to-face STEMM instruction to the online modality. We suggest when working with GRAs, TAs, and LAs to keep the lines of communication open for them to express their specific concerns about teaching online. Cultivating this relationship is vital to ensure faculty and students are on the same page and effectively serve STEMM students online.

\subsection{Ensuring Fair Grading/Assessment}

Give Examinations Online and with Flexible Start Times

- Diversify one's assessment responses when deploying tests online. For declarative knowledge, utilize questions that provide immediate feed-back and grading, such as multiple-choice, matching, and true-false questions. For process-orientated question items, one can use rubric scoring for short-answer and essay questions.

- Furthermore, consider giving the class the option of when they may take the exam. We recommend allowing the students to sign in individually at any given time to begin the examination (for instance, offer the exam to be taken at sometime between 9:00 a.m.-9:00 p.m. on examination day). The exam computer program keeps track of their time and then time out at the appropriate time (for example, you allow the class $55 \mathrm{~min}$ to take an exam for a class that meets for $50 \mathrm{~min}$ ). By providing this flexibility, there are fewer issues in having students log in at a specific time to complete their examination.

\section{Discussion and Conclusions}

The past eighteen months have demarked a most challenging world crisis and a difficult time for anyone in education. Moreover, the COVID-19 pandemic is still present, pushing traditional face-to-face instruction to hybrid and online modalities. Adapting to the COVID-19 pandemic provided some crucial challenges faced in STEMM education, which revolve around the following five salient points (there are many more but here are five points to consider): safety of students and teaching faculty/teaching assistants/staff; keeping students alert and active in this new online format; effectiveness of transferring knowledge from an in-class to an online setting; technology-related issues; and fairness in grading/assessment.

This viewpoint exists due to SARS-CoV-2's virulence and persistence, and the need to provide a safe learning environment for students, faculty, teaching assistants, and staff. Thus, every aspect we describe here is focused on safety and health for all while teachers are teaching and student are learning. We began the "Results" with a simple statement that faculty must know current administrative policy during the COVID-19 pandemic. Staying in tune keeps everyone together and strengthens the lines of communication that are important between student learners and educators.

Since the vast majority of STEMM educators have likely had only limited experience in online teaching, many of our teaching practices summarize what has been effective for us in our recent teaching experiences. These include the seven parts of "Creating Active Learning Online Material with Zoom", the four suggestions in "Creating Ways for Students to Remain Engaged in an Online Class", the recommendations on "Organizing Student Meetings Using Zoom", vary the methods used in "Use a Variety of Technology and Teaching Methods", and tips on teaching laboratory sessions virtually in "Laboratory-based Sections/Courses". Most of these tips involve using technology to enhance instruction and maintain student engagement through social interactions online.

Keeping students engaged can prove difficult in an online setting. Most importantly, student mental health is essential but beyond the scope of the current presentation. We have found that asking the students to remain visible by keeping their cameras on is helpful for them to be present and part of that class, having TAs serve as an interface between the instructor and students to strengthen lines of communication. Being proactive by promptly posting lectures and review sessions keeps everyone up-to-date on course events. Offering 
more regular office hours will keep the students engaged and allow the teaching faculty to get better to know the students (a virtual meeting is better than no meeting). Furthermore, one must remain optimistic as we teach and get to know the students you are currently teaching. Stability and consistency, through positive reinforcement, are good attributes of teaching and especially so during the COVID-19 pandemic.

The students formed collegial bonds and did establish team-building relations during these pressing times. It was clear that most of the students reacted positively, and even meeting over Zoom was preferred to not meeting at all. We believe this encourages and normalizes at-home learning and expands learning opportunities for students. While the COVID-19 pandemic has many of its own challenges, take-home options utilizing the Zoom-breakout room meeting function allow students to control and coordinate the working and learning environment.

Effectively transferring knowledge from a classroom setting to an online setting requires diligence and commitment from the instructor. One change is to be more organized in presenting course material in detail for each class. Retaining all the online material one has developed can be helpful for review sessions. Furthermore, the online material could serve as the scaffolding for flipping that lecture material for future use.

Use of technology is paramount in teaching online. The importance of Zoom, the ability to have a stable internet link between one and the students, having the camera at the right angle, and effectively conversing are just a few of the many things to consider when teaching online. In addition, something that must be considered is the accessibility of the online material for all students in a given class. Use of UDL ensures that all students benefit from the effort made to enhance accessibility. Finally, within the technology aspect is making sure students are keeping up with this new format; thus, considering a one-minute writing exercise prior to a given lecture is one way to assess participation. Furthermore, staying up-to-date with the materials that can also be used a before- or after-class formative assessment.

Grading and assessment needs must also be considered, and we offered one suggestion with two parts. First, give exams online, which seems evident in an online course, but it is not always trivial to make such a move in this direction. Second, give the students flexibility by offering the exam online for several to many hours, and then let them decide what time is best for their life schedule to take the exam. It will turn out to be a win-win scenario.

In a K-12 study from Pakistan, Noor et al. [30] noted that educators had a tough time adapting to an online format, mainly due to physical, mental, and financial challenges from the sudden shift to online teaching. They also noted limitations in infrastructure, mostly linked to power connectivity. In a separate study from the USA, Johnson et al. [31] described a robust view of undergraduate instructors attempting to gain immediate learning skills to join the educational battle against COVID-19. A study by Jiang et al. from a Chinese medical school provided 12 medical science teaching 'pearls' [32]. The common shortcoming of all these papers was the suddenness in which the COVID-19 pandemic escalated; however, there was an immediate bridge of awareness and a rapid attempt to find something to get back to teaching [30-32].

Pichardo et al. [33] studied the strategy involved around student participation and the gaining of competencies. Using the digital high-education software Mentimeter, they noted that in synchronous and non-synchronous classes, Mentimeter promoted participation [33]. Furthermore, results from the study indicated that the software improved collaborative learning [33]. Bento et al. [34] studied the adaptive process needed in response to the COVID-19 pandemic in a different scenario. Their study was focused qualitatively to better understand how the university self-organized itself, in other words, the behavior patterns in education [34]. The results presented describe a variation in behavior from the educators, changes in interactions between teachers and students, and unexpected environmental instability due to the pandemic [34]. In a single case study approach, Peimani and Kamalipour studied postgraduate online education at Cardiff University [35]. The research was performed using an online survey to understand better students' perception 
of online teaching and learning activities [35]. The critical question being asked is how higher education will persist into the post-COVID-19 pandemic future. They conclude that online, blended, and hybrid models for course delivery have boosted higher education's evolution [35]. Nevertheless, the importance of events that we never considered, particularly eye contact, was crucial for the learning process. Maintaining non-verbal communication, like eye contact, remains one of many features we must consider as we continue to evaluate the best way to teach in higher education [35].

In the United Arab Emirates, AlMahdawi et al. [36] investigated the performance of online chemistry classes in a private school. Interestingly, they found a statistically significant improvement in critical thinking, collaborative skills, creativity and innovation, and overall class achievement from online and distance learning of chemistry [36]. These results suggest that student learners during the COVID-19 pandemic achieved better performance than the students perceived [36]. Cicha et al. studied digital and media literacies in the Polish education system [37]. They analyzed a set of skills that would be expected of young people during their education. The effect of the COVID-19 pandemic was more significant in Poland than in other countries because digital competencies were not given a high priority [37]. Finally, Csapodi and Hoffmann measured the changes in the mathematics core curriculum in Hungarian schools [38]. Their work centered on the new National Core Curriculum, which became a reality in September 2020, and more specifically, the effect of the pandemic on mathematics [38]. Fundamentally, the COVID-19 pandemic changed the world, but it has provided an opportunity to reevaluate and rethink the best way to educate our learners. Ultimately, one recommendation from this analysis was to improve the matriculation examination by using a complex essay task in these fields of mathematics [38].

There are limitations to our viewpoint. First, we have not addressed the issues present in many developing countries without the funds to teach online and provide such technology and materials to their faculty. Second, we did not ask student opinions about the online formats that many schools today use to deal with the COVID-19 pandemic. In addition, due to the descriptive nature of this viewpoint, we did not address the need to maintain in transitioning to these teaching styles the hierarchical components in Bloom's Revised Taxonomy on Learning [39-44]. Finally, we did not provide suggestions on improving student mental health issues, which are of paramount importance today during these uncertain times.

In closing, we presented fifteen teaching strategies used by five faculty members from five different institutions. However, by assigning some of our teaching practices here, we hope others may use some of them and adapt certain aspects of the ones presented. Hopefully, this can be a base to build on in their efforts to continue teaching during the COVID-19 pandemic. Finally, online teaching gained momentum before the pandemic, became essential, and will likely be more common in post-pandemic higher education academia [45-51]. Thus, the pandemic-derived teaching practices described here are relevant to future post-pandemic STEMM education.

Author Contributions: Initial conceptualization, F.C.C.; overall conceptualization, F.C.C., S.T.C., Y.M.F., L.N.G. and R.H.; writing-original version, F.C.C., S.T.C., Y.M.F., L.N.G. and R.H.; writingreview and editing (beginning to end), F.C.C., S.T.C., Y.M.F., L.N.G. and R.H.; project administration, F.C.C. All authors have read and agreed to the published version of the manuscript.

Funding: This research received no external funding.

Institutional Review Board Statement: Not Applicable.

Informed Consent Statement: Not Applicable.

Data Availability Statement: Not Applicable. 
Acknowledgments: We thank all the students we have taught over the past 18 months during the COVID-19 pandemic at our respective schools because your participation, patience, and effort made everything presented here possible. We also would like to acknowledge the help of our Information Technology Offices and Centers for the Advancement of Teaching and Learning at our respective universities for (i) providing training and guidance for online teaching, (ii) creating useful resources for the transition to online teaching, and (iii) jump-starting ideas regarding useful teaching strategies.

Conflicts of Interest: The authors declare no conflict of interest.

\section{References}

1. Lotfi, M.; Hamblin, M.R.; Rezaei, N. COVID-19: Transmission, prevention, and potential therapeutic opportunities. Clin. Chim. Acta 2020, 508, 254-266. [CrossRef] [PubMed]

2. Sun, C.; Zhai, Z. The efficacy of social distance and ventilation effectiveness in preventing COVID-19 transmission. Sustain. Cities Soc. 2020, 62, 102390. [CrossRef] [PubMed]

3. Pan, X.-B. Application of personal-oriented digital technology in preventing transmission of COVID-19, China. Ir. J. Med. Sci. 2020, 189, 1145-1146. [CrossRef]

4. Black, J.R.; Bailey, C.; Przewrocka, J.; Dijkstra, K.K.; Swanton, C. COVID-19: The case for health-care worker screening to prevent hospital transmission. Lancet 2020, 395, 1418-1420. [CrossRef]

5. Kaiser, S.V.; Watson, A.; Dogan, B.; Karmur, A.; Warren, K.; Wang, P.; Sosa, M.C.; Olarte, A.; Dorsey, S.; Su, M. Preventing COVID-19 transmission in education settings. Pediatrics 2021, 148. [CrossRef]

6. Mahase, E. COVID-19: Physical distancing of at least one metre is linked to large reduction in infection. BMJ 2020, 369 , m2211. [CrossRef]

7. World Health Organization. COVID-19 Weekly Epidemiological Update, Edition 58, 21 September 2021. 2021. Available online: https://www.who.int/publications/m/item/weekly-epidemiological-update-on-covid-19---21-september-2021 (accessed on 26 October 2021).

8. Liu, P.; Beeler, P.; Chakrabarty, R.K. COVID-19 progression timeline and effectiveness of response-to-spread interventions across the United States. medRxiv 2020. [CrossRef]

9. Peirlinck, M.; Linka, K.; Costabal, F.S.; Kuhl, E. Outbreak dynamics of COVID-19 in China and the United States. Biomech. Model. Mechanobiol. 2020, 19, 2179-2193. [CrossRef] [PubMed]

10. Schwartz, A.M.; Wilson, J.M.; Boden, S.D.; Moore, T.J., Jr.; Bradbury, T.L., Jr.; Fletcher, N.D. Managing resident workforce and education during the COVID-19 pandemic: Evolving strategies and lessons learned. JBJS Open Access 2020, 5, e0045. [CrossRef]

11. de Bruin, Y.B.; Lequarre, A.-S.; McCourt, J.; Clevestig, P.; Pigazzani, F.; Jeddi, M.Z.; Colosio, C.; Goulart, M. Initial impacts of global risk mitigation measures taken during the combatting of the COVID-19 pandemic. Saf. Sci. 2020, 128, 104773. [CrossRef]

12. Ferdig, R.E.; Baumgartner, E.; Hartshorne, R.; Kaplan-Rakowski, R.; Mouza, C. Teaching, Technology, and Teacher Education during the COVID-19 Pandemic: Stories from the Field; Association for the Advancement of Computing in Education Waynesville: Waynesville, NC, USA, 2020.

13. Pace, C.; Pettit, S.K.; Barker, K.S. Best practices in middle level quaranteaching: Strategies, tips and resources amidst COVID-19. Becom. J. Ga. Assoc. Middle Level Educ. 2020, 31, 2-13. [CrossRef]

14. Toquero, C.M. Challenges and opportunities for higher education amid the COVID-19 pandemic: The Philippine context. Pedagog. Res. 2020, 5, em0063. [CrossRef]

15. Jankowski, N.A. Guideposts for Assessment During COVID-19. Assess. Update 2020, 32, 10. [CrossRef]

16. Cuaton, G.P. Philippines higher education institutions in the time of COVID-19 pandemic. Rev. Rom. Educ. Multidimens. 2020, 12, 61-70. [CrossRef]

17. Kaup, S.; Jain, R.; Shivalli, S.; Pandey, S.; Kaup, S. Sustaining academics during COVID-19 pandemic: The role of online teaching-learning. Indian J. Ophthalmol. 2020, 68, 1220. [CrossRef]

18. Neuwirth, L.S.; Jović, S.; Mukherji, B.R. Reimagining higher education during and post-COVID-19: Challenges and opportunities. J. Adult Contin. Educ. 2020. [CrossRef]

19. National Academies of Sciences, Engineering, and Medicine. The Science of Effective Mentorship in STEMM. 2020. Available online: https:/ / www.nationalacademies.org/our-work/the-science-of-effective-mentoring-in-stemm (accessed on 26 October 2021).

20. Root-Bernstein, R.; Van Dyke, M.; Peruski, A.; Root-Bernstein, M. Correlation between tools for thinking; arts, crafts, and design avocations; and scientific achievement among STEMM professionals. Proc. Natl. Acad. Sci. USA 2019, 116, 1910-1917. [CrossRef] [PubMed]

21. Christe, B.L. The importance of faculty-student connections in STEM disciplines. J. STEM Educ. Innov. Res. 2013, 14, $22-26$.

22. Gasiewski, J.A.; Eagan, M.K.; Garcia, G.A.; Hurtado, S.; Chang, M.J. From gatekeeping to engagement: A multicontextual, mixed method study of student academic engagement in introductory STEM courses. Res. High. Educ. 2012, 53, 229-261. [CrossRef]

23. Wilson, D.M.; Summers, L.; Wright, J. Faculty support and student engagement in undergraduate engineering. J. Res. Innov. Teach. Learn. 2020, 13, 83-101. [CrossRef]

24. McGreevy, K.M.; Church, F.C. Active Learning: Subtypes, Intra-Exam Comparison, and Student Survey in an Undergraduate Biology Course. Educ. Sci. 2020, 10, 185. [CrossRef] 
25. Church, F.C. Active Learning: Basic Science Workshops, Clinical Science Cases, and Medical Role-Playing in an Undergraduate Biology Course. Educ. Sci. 2021, 11, 370. [CrossRef]

26. Berrett, D. How 'flipping'the classroom can improve the traditional lecture. Chron. High. Educ. 2012, 12, 1-3.

27. Brame, C. Flipping the Classroom. 2013. Available online: https://cft.vanderbilt.edu/guides-sub-pages/flipping-the-classroom/ (accessed on 26 October 2021).

28. Evans, L.; Bosch, M.L.V.; Harrington, S.; Schoofs, N.; Coviak, C. Flipping the classroom in health care higher education: A systematic review. Nurse Educ. 2019, 44, 74-78. [CrossRef]

29. Hite, R.; Johnson, L.; Velasco, R.C.L.; Williams, G.B.; Griffith, K. Supporting Undergraduate STEMM Education: Perspectives from Faculty Mentors and Learning Assistants in Calculus II. Educ. Sci. 2021, 11, 143. [CrossRef]

30. Noor, S.; Isa, F.M.; Mazhar, F.F. Online Teaching Practices during the COVID-19 Pandemic. Educ. Process. Int. J. 2020, 9, 169-184. [CrossRef]

31. Johnson, N.; Veletsianos, G.; Seaman, J. US Faculty and Administrators' Experiences and Approaches in the Early Weeks of the COVID-19 Pandemic. Online Learn. 2020, 24, 6-21. [CrossRef]

32. Jiang, Z.; Wu, H.; Cheng, H.; Wang, W.; Xie, A.N.; Fitzgerald, S.R. Twelve tips for teaching medical students online under COVID-19. Med. Educ. Online 2021, 26, 1854066. [CrossRef]

33. Pichardo, J.I.; López-Medina, E.F.; Mancha-Cáceres, O.; González-Enríquez, I.; Hernández-Melián, A.; Blázquez-Rodríguez, M.; Jiménez, V.; Logares, M.; Carabantes-Alarcon, D.; Ramos-Toro, M. Students and Teachers Using Mentimeter: Technological Innovation to Face the Challenges of the COVID-19 Pandemic and Post-Pandemic in Higher Education. Educ. Sci. 2021, 11, 667. [CrossRef]

34. Bento, F.; Giglio Bottino, A.; Cerchiareto Pereira, F.; Forastieri de Almeida, J.; Gomes Rodrigues, F. Resilience in Higher Education: A Complex Perspective to Lecturers' Adaptive Processes in Response to the COVID-19 Pandemic. Educ. Sci. 2021, 11, 492. [CrossRef]

35. Peimani, N.; Kamalipour, H. Online Education in the Post COVID-19 Era: Students' Perception and Learning Experience. Educ. Sci. 2021, 11, 633. [CrossRef]

36. AlMahdawi, M.; Senghore, S.; Ambrin, H.; Belbase, S. High School Students' Performance Indicators in Distance Learning in Chemistry during the COVID-19 Pandemic. Educ. Sci. 2021, 11, 672. [CrossRef]

37. Cicha, K.; Rutecka, P.; Rizun, M.; Strzelecki, A. Digital and Media Literacies in the Polish Education System-Pre- and PostCOVID-19 Perspective. Educ. Sci. 2021, 11, 532. [CrossRef]

38. Csapodi, C.; Hoffmann, M. Changes in Mathematics Core Curriculum and Matriculation Exam in the Light of the COVID-19Shock. Educ. Sci. 2021, 11, 610. [CrossRef]

39. Krathwohl, D.R. A revision of Bloom's taxonomy: An overview. Theory Pract. 2002, 41, 212-218. [CrossRef]

40. Forehand, M. Bloom's taxonomy. Emerg. Perspect. Learn. Teach. Technol. 2010, 41, 47-56.

41. Anderson, L.W.; Sosniak, L.A. Bloom's Taxonomy; University of Chicago Press: Chicago, IL, USA, 1994.

42. Fink, L.D. Creating Significant Learning Experiences: An Integrated Approach to Designing College Courses; John Wiley \& Sons: Hoboken, NJ, USA, 2013.

43. Anderson, L.W.; Bloom, B.S. A Taxonomy for Learning, Teaching, and Assessing: A Revision of Bloom's Taxonomy of Educational Objectives; Longman. 2001. Available online: https://www.jstor.org/stable/42926529 (accessed on 26 October 2021).

44. Conklin, J. A taxonomy for learning, teaching, and assessing: A revision of Bloom's taxonomy of educational objectives complete edition. Educ. Horiz. 2005, 83, 154-159.

45. Arnove, R.F. Imagining what education can be post-COVID-19. Prospects 2020, 49, 43-46. [CrossRef]

46. Curtin, R. Reimagining higher education: The post-covid classroom. Educ. Rev. 2021. Available online: https://er.educause.edu/ articles/2021/4/reimagining-higher-education-the-post-covid-classroom (accessed on 26 October 2021).

47. Dumulescu, D.; Pop-Păcurar, I.; Necula, C.V. Learning design for future higher-education-insights from the time of COVID-19. Front. Psychol. 2021, 12, 2843. [CrossRef]

48. Xie, X.; Siau, K.; Nah, F.F.-H. COVID-19 pandemic-online education in the new normal and the next normal. J. Inf. Technol. Case Appl. Res. 2020, 22, 175-187. [CrossRef]

49. Goh, P.-S.; Sandars, J. A vision of the use of technology in medical education after the COVID-19 pandemic. MedEdPublish 2020, 9,1-8. [CrossRef]

50. Rapanta, C.; Botturi, L.; Goodyear, P.; Guàrdia, L.; Koole, M. Online university teaching during and after the COVID-19 crisis: Refocusing teacher presence and learning activity. Postdigit. Sci. Educ. 2020, 2, 923-945. [CrossRef]

51. Nworie, J. Beyond COVID-19: What's Next for Online Teaching and Learning in Higher Education. 2020. Available online: https:/ / er.educause.edu/articles/2021/5/beyond-covid-19-whats-next-for-online-teaching-and-learning-in-higher-education (accessed on 26 October 2021). 